\title{
The Essence of Overeducation in China
}

\author{
Zhang ping ${ }^{1, a}$, Anrong $\mathrm{Hu}^{2, \mathrm{~b}}$ \\ ${ }^{1}$ School of Economics and Management, Wuhan University ,Wuhan,430072, China \\ ${ }^{2}$ School of Economics and Management, Wuhan University; Huazhong Agriculture \\ University, Wuhan, 430072, China \\ aemail: pzjackie@yahoo.com.cn, bemail: anronghu@163.com
}

Keywords: overeducation; education deepen; Beveridge Curve; industrial restructure; job search

\begin{abstract}
This paper provides an Analysis of the over-education of graduates in China . It first reviews some theoretical explanation about over-education, then proceeds to argue how over-education can form in the context of the industrial upgrading and labor market segmentation by using Beveridge Curve. The coexistence of a large number of job vacancies and unemployment is the result of both education deepening and job searching with mismatch. To establish the over-education more directly, a logical framework diagram has been constructed. The paper concludes with a brief discussion of policy measures for both individuals and the government.
\end{abstract}

\section{Introduction}

The number of college graduates in China has got a substantial annual growth since the expanding policy of higher enrollment was carried out in 1999, the difficult employment issues have become increasingly prominent. University graduates engage in works out of their own professional, the frequent occurrence of "talent high consumption" phenomenon means there is a mismatch between the education level and working-level. Employment rate of university graduates has declined from 90\% in 2001 to $68 \%$ in 2009 [1]."Graduation means unemployment” for college students has aroused questioning the value of higher education, some people think China is experiencing over-education.

The American scholars Freeman proposed "over-education" theory in response to the phenomenon that education flourish in American coexisted with a large number of unemployment of highly educated people. The first measure to the mismatch between the level of education of the staff and the level of education the work required [2], attracted much attention of scholars in western developed countries. Subsequently, over-education was discussed, people found that there are over education issues not only in developed countries with rich educational resource, but also in many developing countries with poor talent and education resource.

\section{Overeducation:Theoretical Explanation}

Overeducation has commonly been defined in one of three ways: as a decline in the economic position of educated individuals relative to historically higher levels, as underfulfilled expectation of the educated with respect to their occupational attainments, or as the possession by workers of greater educational skills than their jobs required [3].

The concept of overeducation caused wide concern immediately, and over-education phenomenon was given interpretation by different theoretical schools. Among them, the typical three are human capital theory, job-screening model and job-competition model.

According to the human capital theory, overeducation is a short-run problem in the labor market when there is only a temporary mismatch between the supply of and demand for educated workers [4].Human capital theory believes that individuals obtain more knowledge and skills through accepting education, more education means more human capital in the labor market, so they have higher labor productivity and more profitable skills [5]. Human capital theory also has used 
trade-off of human capital investment to explain the over-education [6]. School education, work experience and on-the-job training are different forms of human capital investment, and they can be substituted or compensated for each other. Excessive educators use the additional education to compensate for lack other human capital investment, such as job training and work experience, and vice versa.

According to Spence's job-screening model [7], the labor market is characterized by imperfect information, and education is used as a signal to identify more able and motivated individuals or more productive ones to employers. In order to acquire more of the signal, individuals will invest more in education, hoping that an additional amount of educational signal suffices to distinguish them from others. Thus there is a tendency for the level of educational attainment of the labor force to rise relative to what is required of jobs, if job requirements do not change.

So Human capital theory and job-screening theory have the same point of view, there is a significant positive correlation between education and economic benefits, since more education is associated with higher labor productivity. Obvious differences between them too, human capital theory thought education can improve the ability of the educated, while job-screening theory thought education just to send the signal of innate ability for the individual.

The job-competition model of Thurow considers two queues: a job queue and a person queue [8]. Each job in the job queue has its own skill requirements, productivity characteristics and pay scale. Individuals competing for jobs also form a queue, their relative position in the queue being determined by a set of characteristics such as education and experience that suggest to the employer the cost of training them in the skills necessary to perform a given job. The higher a person is in the person queue. The less is the cost of training and the more likely the person will be to get a job at the head of the job queue. Thus in order to place themselves higher up in the person queue, individuals will invest in education hoping that an additional amount of education will enhance their chance of getting a good job relative to others.

\section{The Essence of Overducation}

The above theories explain the phenomenon of over-education from different perspectives. The nature of unemployment among graduates is over education? The higher education in China is still an elite education although it has been greatly developed in recent years. At present, the proportion of college students accounted peers for around 11\%, while in developed countries accounting for $30 \%$ to $50 \%$. On the other hand, the high level talent is scarce and multinational talent is hard to find. “Talent Development Report in China(2010)" has disclosured the fact," According to a survey conducted by the McKinsey \& Company, there are only 10\% of Chinese university students could meet the personnel requirements of multinationals. "

This article argues that the essence of the current over-education is an education deepen on the background of Industrial restructuring, the coexistence of a large number of job vacancies and unemployment is the result of both education deepening and job searching with mismatch.

Education deepen is a common phenomenon in the process of economic development in developing countries, there are two different economic structure In China, the traditional sector and the modern sector. Workers squeeze in the modern sectors for a job rather than condescension in the traditional sectors which mean lower pay and worse benefits. Due to the limited positions in modern sector, high educated workers do the work which originally done by low educated workers. Because of the low cost of higher education in our country and personal income is significantly higher than the personal cost, there is unlimited demand for public education, highly educated people will exceed the needs of the modern sector and leading to unemployment. The state had to expand the educational institutions at all levels because of education deepening, resulting in blind expansion for the education scale and the decline of education quality, especially for higher education.

Then the paper will analysis the coexistence of Unemployment among graduates and job vacancies by using Beveridge Curve. The curve describes the negative relationship between unemployment and vacancies in the labor market. It was first used by the British economist 
Beveridge in a book"full employment in a free society" (1944), mainly used for the analysis of unemployment and labor market structural problems [9].

The derivation of the Beveridge Curve began from a matching function:

$$
M=M(U, V) \quad \mathrm{MU}>0, \mathrm{MV}>0
$$

$M$ represents the number of matches to work, $U$ represents the number of unemployed workers, $\mathrm{V}$ represents the number of job vacancies.

As shown in Figure 1, the abscissa represents unemployment, the vertical axis represents the vacancies.

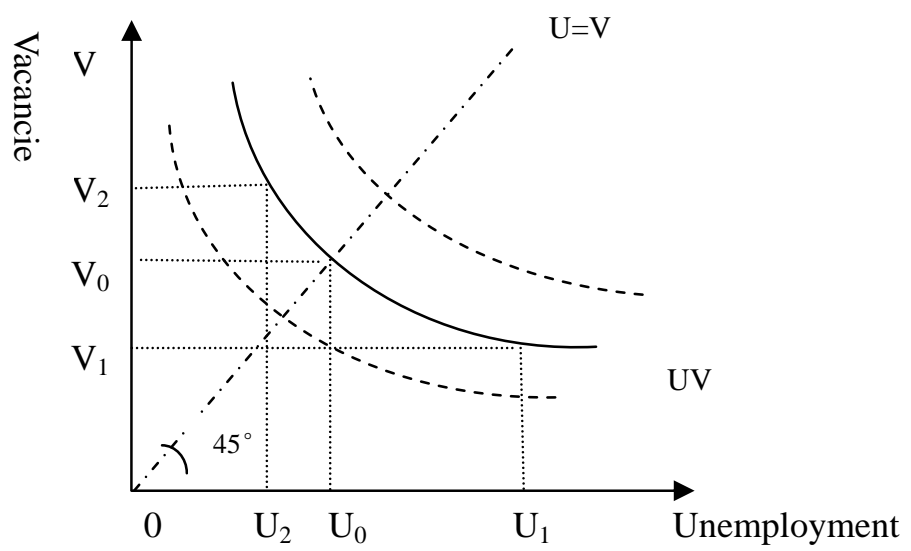

Figure 1. Beveridge Curve analysis on graduate unemployment

Unemployment generally can be divided into cyclical unemployment caused by the lack of demand, structural unemployment and frictional unemployment. Cyclical economic fluctuations lead combination points of unemployment and job vacancy rates to move along the Beveridge Curve, changes of Job matching efficiency will lead to the displacement of the Beveridge Curve, parallel movements in unemployment and vacancies.

When the cyclical unemployment rate caused by the lack of demand is $0, \mathrm{U}=\mathrm{V}$, points described by $45^{\circ}$ line in the diagram, the overall unemployment rate is U0, job vacancies is V0. The main reason of unemployment is the institutional factors in the labor market and asymmetric information. When in the recession, it means employment reduction, rising unemployment and job vacancies decline. In Figure 1, the unemployment rate move to U1 along the Beveridge Curve, U1-V1 is the unemployment caused by lack of demand. When in economic prosperity, employment opportunities increase, unemployment rate decline, the job vacancy rate increase, the unemployment rate decreased to U2 and it can be seen as structural unemployment and frictional unemployment. As shown in Figure 1, the shift of Beveridge Curve indicates the ability matching to unemployed with vacancies in the labor market has changed. The curve moves more to the original point, the smaller intercept, the higher operational efficiency of the labor market, and vice versa.

For university graduates in China, a large number of high-end jobs vacancies coexist with highly educated workers unemployed. The cyclical unemployment is not the most important reason because China's GDP has maintained an average annual growth of 9.9\% from 1978 to 2010. The unemployment mainly comes from two aspects, firstly, structural unemployment in the context of industrial structure adjustment which moves along the Beveridge curve; secondly, search inefficiencies and mismatch on both sides in the labor market lead to unemployment,the displacement of the Beveridge Curve.

The industrial structure adjustment will cause the change of employment needs. One hand, industrial restructure can transfer the production factors from low-productivity sectors to high-productivity sectors, accelerating the development of emerging industries by resources re-allocation effect, increasing demand for labor. On the other hand, industrial restructuring, accompanied by capital deepening, technological progress, the drastic change of the industry as well as the old industrial recession, will increase unemployment. The industrial restructuring brings the change of the labor needs in different industries and affects the transfer of labor among departments. The unemployment rate is still higher than the natural rate of unemployment when the economy is in the stable equilibrium state. In the process of industrial upgrading, higher and higher 
demands on staff skills is needed with the development and growth of the modern sector, but education is a long-term process, the educational structure can't optimize instantly .There is a lag of the talent supply structure to keep up with the changes of the structure of demand. During the "12th Five-Year", China has proposed, “ Continue to strengthen and expand the high-tech industrial, foster the development of strategic emerging industries to pilot and pillar industries." With the rise of information technology industry, biotechnology, high-end equipment manufacturing, new energy, new materials, new energy vehicles and other strategic emerging industries, the overall demand of application expertise is more urgent for corresponding industrial and technical fields.

About displacement on the Beveridge Curve, the main perspective is job search for matching in the labor market in this paper. There are both job seekers and vendors in the economy, job destruction appears at a certain rate over time, and the job-seekers find work at a certain rate. College students need to choose between being employed and unemployed, vendors need to choose between vacancies and employment of workers. Workers meet with vendors in the labor market, because of information asymmetry and search frictions, workers and manufacturers determine the level of wages through bargaining. This process is not completed immediately, the unemployment and vacancies still exist in equilibrium state. If matching efficiency drops, given the degree of labor shortages in the market, the rate of the workers to find a job will decline and it will lead to the relocation of the Beveridge Curve. The increase of Job destruction rate may lead to accelerated re-configuration of the positions in different departments, leading to the relocation of the Beveridge Curve[10].

Perfect labor market is a necessary condition to achieve the optimal allocation of the labor force. The labor market operation mechanism determines the flow of labor and the allocation efficiency. China is in the transition from planned economy to market economy, multiple segmentation could be found in the labor market ,such as regional segmentation and system segmentation. College graduates tend to take high level social security units and industry as a reference system. On the other hand, many of the current graduates are the only child of one family, there are some tendencies when seeking a job, they like to crowd in the first-tier cities, "civil servant" hot. Some students have superior home environment and don't rush to find jobs, the flexibility of the labor market is low. The reservation wage of Job seekers is higher than their level of competence, the segmentation of the labor market leads to higher employment costs for vendors, a variety of factors lead to the low matching efficiency. So the job vacancies and unemployment coexist, some job seekers can't find a suitable job and choose to continue their education, to improve their employment competitiveness.

In summary, the logical process of over-education and education deepening can be described in the following figure:

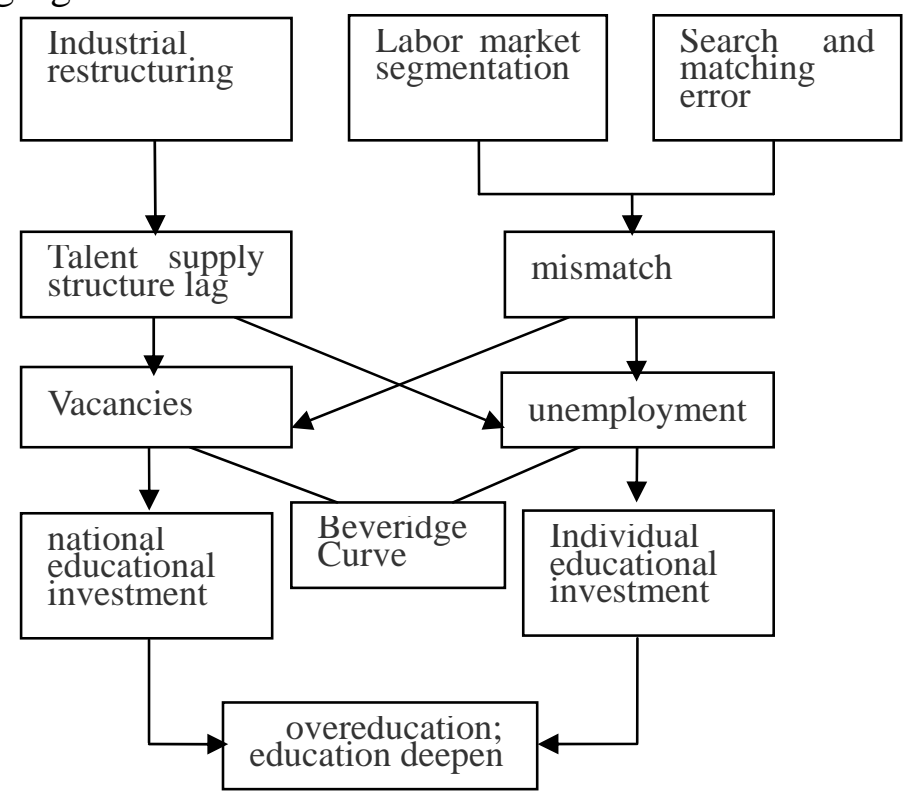


Figure 2. Education deepen evolutionary diagram

\section{Conclusions and Countermeasures}

This paper argues that the essence of the over-education phenomenon is the adjustment of industrial structure in the context of education deepening. For college students, the coexistence of a large number of job vacancies and unemployment is the result of both education deepening and job searching with mismatch. Structural unemployment caused by industrial restructuring moves along the Beveridge curve; based on the status of segment labor market in China and the student characteristics, there is an inefficient matching in the labor market, resulting in the relocation of the curve. Education deepening is the result of the joint investment decision-making of the state and individuals.

In order to optimize the configuration of educational resources, some measures need to be taken immediately. First, optimize the educational structure to adapt to the requirements of the industrial structure upgrading, the education professional setting system needs a reform market-oriented, improve and strengthen vocational education to meet the demand for skilled personnel. Second, strengthen employment guidance education, leading to rational planning career for university graduates. It is necessary to improve college career guidance institutions and enrich guidance teachers, employment funding and place. Third, improve the labor market, increase the efficiency of searching and matching. Social security system covering the whole society and Labor market information network should be established gradually.

\section{References}

[1] Xiaobei Zhang and Peng Qi,“ On the Problem of Over Education in China: Based on the Empirical Test of General Social Survey of China,” Research in Educational Development, No.17, pp.32-36,2010.

[2] Freeman, Richard B. , The Overeducated American. New York: Academic Press, 1976.

[3] Rumberger, Overeducarion in the U.S. Labor Market. New York: Praeger,1981.

[4] Tsang, M. \& H.Levin, “The Economics of Overeducation, ”Economics of Education Review. 4( 2) , pp. 93-104,1985.

[5] Schul tz , T . "Investment in Human Capital,” A merican Economic Review , 51(1) , pp.1-17,1961.

[6] Xiangrong WU, “A Theoretical Review of Western Over education, ” Studies in Foreign Education, Vol.33, No.5, General No.191, pp.6-10, 2006.

[7] Spence, M. , Job market signaling. Quurt. J. Econ. 87. pp.355-374,1973.

[8] Thurow, L. Generating Inequality: Mechanisms of Distribution in the U.S. Economy. New York:Basic Books ,1975.

[9] Deyuan Zhang, "Beveridge curve and its application in China," Quantitative \& Technical Economics, No.5, pp. 124-129. 2004.

[10] Baoliang Li, Qiyou Guo, “The search in frictional market: the development and its application of search and matching model,” Foreign Economics \& Management, Vol. 32, No.11, Nov, pp.1-9, 2010 . 